\title{
FID-Gas Chromatography of West-Algerian Cucurbita реро (or Pumpkin) Seed Oil Extract
}

\author{
Abdelkrim Berroukche, Abdelkader Ammam, Mohamed Terras, Mohamed Amine Souidi, \\ Mohamed Chibani, Hafsa Habri, Aicha Amara, Hafsa Dellaoui, and Farouk Boudou
}

\section{ABSTRACT}

Fatty acid and phytosterol vegetable oils were extracted from seeds of Cucurbita pepo (or pumpkin) into (v/v) hexane. The extract obtained was characterized by the contents of sterols, unsaturated and saturated fatty acids. The content of the bioactive compounds was determined by gaschromatography FID method. Pumpkin seed oil extracts showed higher content of poly-unsaturated fatty acids $(\mathbf{4 9 . 1 0 \%})$ than that from saturated fatty acids $(28 \%)$. Sterols exhibited different molecules dominated by $\beta$ sistostérol $(47 \%)$, Stigmastérol $(23.6 \%)$ and campesterol $(21.5 \%)$. Several peaks were present on the FID GC chromatogram of two extracts (fatty acids and sterols respectively). GC spectra confirmed the presence of the predominant bioactive compounds (PUFA, $\beta$-sistostérol, Stigmastérol and campesterol). The composition of pumpkin seed oil extract was characterized by FID-GC spectra with maximum at $280 \mathrm{~nm}$.

Keywords: Cucurbita pepo, fatty acid, gas-chromatography, phytosterol, pumpkin.

Published Online: August 31, 2021

ISSN: $2684-4478$

DOI :10.24018/ejchem.2021.2.3.69

\section{A. Berroukche*}

Research laboratory of water resources and environment, Biology department, Faculty of science, University of Saida, Algeria.

(e-mail: kerroum1967@yahoo.fr)

A. Ammam

Biology department, Faculty of science, University of Saida, Algeria.

(e-mail: vetokadi@yahoo.fr)

M. Terras

Research laboratory of water resources and environment, Biology department, Faculty of science, University of Saida, Algeria.

(e-mail: mohamedterras ${ }^{\circledR}$ hotmail.com)

M. A. Souidi

Biology department, Faculty of science, University of Saida, Algeria.

(e-mail: aminesouidi13@gmail.com)

M. Chibani

Biology department, Faculty of science, University of Saida, Algeria.

(e-mail: chibanimohamed20@gmail.com) H. Habri

Biology department, Faculty of science,

University of Saida, Algeria.

(e-mail:

berroukche_kerroum ${ }^{@}$ outlook.com)

A. Amara

Biology department, Faculty of science,

University of Saida, Algeria.

(e-mail: abdelkrim.berroukche@ univsaida.dz)

H. Dellaoui

Research laboratory of water resources and environment, Biology department, Faculty of science, University of Saida, Algeria.

(e-mail: biochimiesaida2015@gmail.com) F. Boudou

Research laboratory of Health \& Environment, University Hospital complex, University of Sidi-Bel-Abbes, Algeria.

(e-mail: Farouk.boudou ${ }^{\circledR}$ yahoo.fr)

*Corresponding Author

\section{INTRODUCTION}

This report focused on an aromatic plant named pumpkin, or Cucurbita pepo, widely used as a vegetable in several cooking dishes without forgetting its pharmacological benefits for the human organism. The pumpkin seeds are rich in unsaturated oil (30-50\%) and have long been used for their anthelmintic properties [1]. In recent years, European countries have been marketing pumpkin seed oil as a drug to treat benign prostatic hypertrophy (BPH) [2], [3]. Pumpkin seed oil effects, on BPH symptoms, are attributed to $\Delta^{7}$ sterols and their glucosides although their mechanism is not 
yet elucidated [4], [5]. This oil essentially contains four fatty acids in significant proportions, two are saturated; palmitic acid $\mathrm{C} 16: 0(13,3 \%)$ and stearic acid C18:0 (8\%) and two are unsaturated; oleic acid C18:1 (29\%) and linoleic acid C18:2 (47\%). These proportions vary according to the geographical origin, climatic conditions, and the nature of the soil. Unsaturated fatty acids represent $98 \%$ of all fatty acids [6], [7]. Phytosterols, less than 1\%, have significant pharmacological activity. It has been found $\Delta^{7}$-sterols and their glucosides, in particular glucoside of spinasterol or $24 \beta$-ethyl-5 $\alpha$-cholesta-7,25(27)-dien-3 $\beta$-ol accompanied by $\Delta^{5}$-sterols (clerosterol, isofucosterol, stigmasterol, campesterol,...) [8]. Other compounds such as triglycerides, tocopherols (vitamin E and $\gamma$-tocopherol), carotenoids, and a cyclic amino acid (cucurbitine or 3-amino-3carboxypyrrolidine) have displayed anthelminthic activities [9]. The pumpkin seed oil revealed benefits against different pathologies such as tumors, diabetes, hyperlipidemia and urinary disorders [10]. In many researches, Cucurbita pepo seed oil also recorded anti-inflammatory and antibacterial activities [11]. It has already showed its efficiency on numerous bacterial strains such as $S$. aureus, Bacillus subtillus, E. coli and P. aeruginosa by using seed extracts prepared in different solvents (water, chloroform, and alcohol) [12]. This work aimed to determine the content of West Algerian Cucurbita pepo seed extract.

\section{MATERIAL AND MethodS}

\section{A. Plant Material}

Cucurbita pepo, as fresh herb, was harvested in the locality of Sidi-Amar, $26 \mathrm{~km}$ from the region of Saida (district located in western Algeria), during mid-autumn mid-winter 2017. The geographic coordinates of the study area were as fellow; latitude $\left(35^{\circ} 13^{\prime} 1^{\prime}\right.$ North), longitude $\left(0^{\circ} 6^{\prime} 26^{\prime}\right.$ East $)$, altitude $(583 \mathrm{~m})$, area $\left(176 \mathrm{~km}^{2}\right)$ and climate (semi-arid, dry, and cold). The plant was identified at Water Resources and Environment Laboratory, affiliated to the biology department, faculty of science, Tahar-Moulay University of Saida, Algeria. The plant part studied was the seeds. They were separated from the flesh, cleaned, washed, and then dried in the shade in a dry and ventilated place. The seeds were then weighed, finely ground in a brand "type 4 in 1 juicer / blinder, SJB-309" and recovered in glass petri dishes.

\section{B. Preparation of Plant Extract}

An amount of $30 \mathrm{~g}$ of crushed Cucurbita pepo seeds was put in a cartridge of the Soxhlet extractor. The instrument was connected to a glass flask containing $400 \mathrm{~mL}$ of hexane. The whole seeds and solvent were heated at $70{ }^{\circ} \mathrm{C}$ to boiling and reflux. The extraction cycle was repeated three times for three to four hours per cycle. The seed oils obtained were separated from the solvent. The latter would be removed by evaporation using a rotation system. The seed oil was stored at temperature of $4{ }^{\circ} \mathrm{C}$ in a sterile, hermetically sealed glass bottle away from light. The yield of vegetable oil extraction was determined based on the volume of the oil extracted (32.4 mL) and its density (0.91).

\section{Organoleptic and Chemical Properties of Extracted Oil}

Each oil is characterized by its smell, appearance, color, and degree of acidity $(\mathrm{pH})$.

\section{Extracted Seed Oil's Composition by Gas- chromatography $(G C)$}

The quantitative analysis of the compounds (fatty acids and phytosterols) of the extracted oil was carried out using gas chromatography with a flame ionization detector (GC/ FID) of the brand "Vrian-CP-3800". This method of analysis and separation of the constituents of the oil was carried out in the chemical and biological analysis laboratory, called AFAK, located in the city of Oran, western Algeria.

\section{E. Dosage of fatty acids}

\section{1) Trans-esterification of fatty acids from the extracted oil}

The technique followed was adapted to that of Metcafle et al. in 1966, and improved consisting in carrying out a methylation of fatty acids (saponifiable part) [13]. The oil was added with alcoholic soda $(\mathrm{NaOH}$ and methanol), then incubated in a water bath at $65{ }^{\circ} \mathrm{C}$ for $15 \mathrm{~min}$. Boron trifluoride (BF3) was added to the mixture, left in a water bath for $5 \mathrm{~min}$ at $65{ }^{\circ} \mathrm{C}$. After cooling, distilled water and hexane were added. After centrifugation, the organic phase (methyl esters of fatty acids) was separated by sodium sulfate and then analyzed in GC / FID.

\section{2) -Identification of methyl esters of fatty acids}

The identification of fatty acids was carried out by comparison of the retention times obtained with those of standards. The quantification of fatty acids was carried out from the calibration curves determined for the methyl esters of fatty acids injected under the same conditions as the standard samples of methyl esters of fatty acids, namely PUFA2 (fatty acids of animal origin) and PUFA3 (fatty acids menhaden oil).

\section{3) Chromatographic conditions}

The device followed certain conditions for the correct functioning of the chromatography GC/FID, mentioned as follow; Innowax capillary column $(0.25 \mathrm{~mm} \times 30 \mathrm{~cm})$, thickness $(0.25 \mu \mathrm{m})$, column temperature (programmed from 160 to $250{ }^{\circ} \mathrm{C}$ with a gradient of $1{ }^{\circ} \mathrm{C} / \mathrm{min}$ for the first 20 minutes and programmed at $2{ }^{\circ} \mathrm{C}$ for the last $35 \mathrm{~min}$ ), gas-vector (hydrogen), gas flow-vector $(1 \mathrm{~mL} / \mathrm{min})$, injected volume $(0.4 \mu \mathrm{L})$, injector temperature $\left(220^{\circ} \mathrm{C}\right)$ and detector temperature $\left(250^{\circ} \mathrm{C}\right)$.

\section{F. Dosage of phytosterols}

\section{1) Principle}

The oil was added with betulin, sodium hydroxide and ethanol. The unsaponifiable part was removed with diethylether. The saponifiable part (sterols) was isolated with aluminum oxide. The phytosterols obtained would be transformed into trimethyl sily-ethers. The phytosterols were analyzed with GC/FID on capillary column. The identification of phytosterols was based on the isolation of the unsaponifiable and the silylation of the unsoponifiable fraction before direct injection into GC. 


\section{2) Saponification}

To initiate the saponification of oil extract, the mixture ( $250 \mathrm{ml}$ of oil, $1 \mathrm{mg}$ of betulin, $1 \mathrm{ml}$ of acetone and $5 \mathrm{ml}$ of alcoholic soda) was boiled under reflux for 15 minutes. At the end of this step, $5 \mathrm{ml}$ of ethanol were added to the mixture.

\section{3) Extraction of sterols}

To isolate the unsaponifiable fraction, $5 \mathrm{ml}$ of the solution was poured into a glass column filled with aluminum oxide hydrated with ethanol. The elution of the solution on a funnel carrying a filter (Whatmann paper No. 41) makes it possible to separate the alumina particles from the unsaponifiable fraction which would be extracted with $5 \mathrm{ml}$ of ethanol then $30 \mathrm{ml}$ of diethyl-ether. Solvents were evaporated under vacuum using a rotavapor. the extract was recovered with $2 \mathrm{ml}$ of diethyl ether.

\section{4) Identification of sterols}

$100 \mu \mathrm{l}$ of silylating reagents (95 $\mu \mathrm{l}$ of N-methyl-Ntrimethyl-silyl-heptofluorobutyramy and $5 \mu \mathrm{l}$ of methyl imidazol) were added to the isolated sterols. The whole was heated for $15 \mathrm{~min}$ at $105{ }^{\circ} \mathrm{C}$. A volume of the prepared solution $(1 \mu \mathrm{l})$ was injected with a micro-syringe on a capillary column. Phytosterol compounds were quantified by a flame ionization detector at $310^{\circ} \mathrm{C}$ with a flow rate of 1 $\mathrm{ml} / \mathrm{min}$. Each phytosterol was identified from its retention time using mixtures of standards.

\section{5) Chromatographic conditions}

Column ( $\mathrm{Rxi}^{\circledR}-5 \mathrm{~ms}, 30 \mathrm{~m}, 0.25 \mathrm{~m}$ DI, $\left.0.25 \mu \mathrm{m}\right)$, sample (unsaponifiable extract), injection volume $(1 \mu \mathrm{l})$, injection temperature $\left(310^{\circ} \mathrm{C}\right)$, oven temperature: $250^{\circ} \mathrm{C}$ (maintained $1 \mathrm{~min})$ to $320{ }^{\circ} \mathrm{C}$ (maintained $\left.1.6 \mathrm{~min}\right)$, vector gas (He, constant flow), debit (1 $\mathrm{ml} / \mathrm{min})$, detector (MME), mode (SIM) and ionization mode (IE).

\section{RESULTS AND DISCUSSION}

The vegetable oil extracted from the pumpkin seeds, by the Soxhlet method, has undergone rota-evaporation to separate the "hexane" solvent. The oil obtained was an olive green color. The use of the hexane solvent is the performant way to separate oils and provides a good extraction. The vegetable oil extraction yield from Cucurbita pepo seeds was $26.81 \%$.

Pumpkin seed oils' fatty acid composition can be used to assess stability and nutritional quality. A higher degree of oil unsaturation makes it more susceptible to oxidative degradation. The fatty acid composition varies depending on several factors, including variety, growing area, climate, and seed maturity [14]. GC analysis (Fig. 1) Showed that the dominant fatty acids found in the oils studied were, for saturated fatty acids; palmitic acid C16:0 (13.1\%), myristic acid $\mathrm{C} 14: 0(8.8 \%)$ then for unsaturated fatty acids; there are linoleic acid C18:2 (45\%) and oleic acid C18:1 (19.6\%). The fatty acid composition of the eight samples of pumpkin seeds studied were grouped together in the Table I. This fatty acid profile agrees with other studies [15]. The pumpkin seed oils contain a total proportion of saturated fatty acids (SFA) that was $28 \%$, including palmitic acid (more than $10 \%$ ) followed by myristic acid (more than 7\%), on the other hand the sum of monounsaturated fatty acids (MUFA) and polyunsaturated fatty acids (PUFA) were $70.1 \%$ of all fatty acids. This high rate of unsaturated fatty acids was also found in other studies in Cucubitaceae species [15]. The major fatty acids were linoleic acid and oleic acid. In other studies [16], the linoleic acid rates (43.1$55.6 \%$ ) were higher than those found in this study. Pumpkin seed oils were a rich source of linoleic acid and oleic acid suggesting that can be used as edible oils. The low proportions recorded for other fatty acids were also in agreement with other results reported in the literature [14].

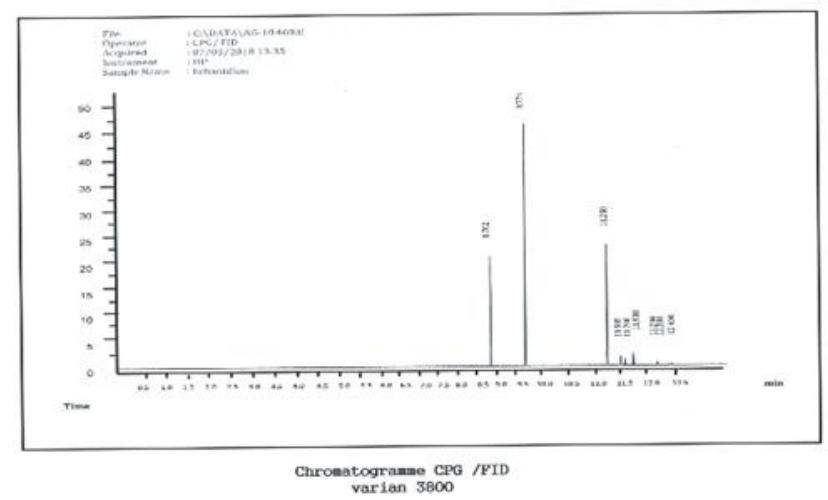

Fig. 1. Fatty acids chromatogram of pumpkin seed oil.

\begin{tabular}{cccc}
\multicolumn{4}{c}{ TABLE I: GC ANALYSIS OF FATTY ACIDS PUMPKIN SEED OIL } \\
\hline $\mathrm{N}$ & Fatty acids & $\begin{array}{c}\text { Time retention } \\
(\mathrm{min})\end{array}$ & Rate $(\%)$ \\
\hline 1 & myristic acid C14:0 & 8.915 & 8.80 \\
2 & myristoleic acid C14:1 & 9.115 & $\mathrm{ND}$ \\
3 & palmitic acid C16:0 & 9.320 & 13.10 \\
4 & palmitoleic acid C16:1 & 9.650 & 0.5 \\
5 & stearic acid C18:0 & 9.850 & 3.0 \\
6 & oleic acid C18:1 & 10.510 & 19.60 \\
7 & linoleic acid C18:2 & 11.130 & 45.00 \\
8 & a-linolenic acid C18:3 & 11.370 & 4.10 \\
9 & arachidic acid C20:0 & 11.565 & 1.70 \\
10 & behenic acid C22:0 & 12.150 & 1.40 \\
11 & erucic acid C22:1 & 12.355 & 0.90 \\
& Total identified & & 98.10 \\
\hline
\end{tabular}

ND: non determined.

However, the stability of oils and their resistance to the oxidation process depend not only on the fatty acid composition, but also on the presence of minor components that can have antioxidant effects. The antioxidant activity of a vegetable oil is based on the elimination of free radicals. Thus, antioxidants can prevent alteration chain reactions and thus the accumulation of free radicals and consequently prevent damage induced by peroxidation of membrane lipids.

The unsaponifiable part of the oils, analyzed by GC, showed that the phytosterols, namely $\beta$-sistosterol (47\%), stigmasterol $(23.6 \%)$ and campesterol $(21.5 \%)$ are in the majority (Table II) (Fig. 2). These compounds, whose chemical structure closely resembles that of cholesterol, are specific to vegetable oils extracted from the seeds of the pumpkin. Phytosterols are believed to confer beneficial effects on this oil in the treatment and prophylaxis of prostate gland and bladder dysfunction [17].

$\beta$-sistosterol, is also a marker of pumpkin seed oils (Cucurbita maxima) and bitter melon seed oils. Its content 
varies from 75.7 to $87.3 \%$ [14]. The other phytosterols, at low levels in this study, namely, Brassicasterol $(1.9 \%), \beta$ sitostanol (1.4\%), lanasterol (2.6\%), desmosterol $(0.8 \%)$, cholestanal $(0.3 \%)$ and cathosterol $(0.5 \%)$ are considered to be important bioactive compounds even whether they are poorly represented (Table II) (Fig. 2). These differences in the rates of phytosterols can be attributed to the stages of seed maturity or to the nature of the solvent used in the extraction method or procedure.

TABLE II: GC ANALYSIS OF PHyTOSTEROLS PUMPKIN SEED OIL EXTRACT

\begin{tabular}{cccc}
\hline $\mathrm{N}$ & Phytosterols & $\begin{array}{c}\text { Time retention } \\
(\mathrm{min})\end{array}$ & Rate $(\%)$ \\
\hline 1 & campesterol & 8.702 & 21.50 \\
2 & $\beta$-sistosterol & 9.774 & 47.00 \\
3 & stigmasterol & 11.250 & 23.60 \\
4 & brassicasterol & 11.585 & 1.90 \\
5 & $\beta$-sitostanol & 11.708 & 1.40 \\
6 & lanasterol & 11.908 & 2.60 \\
7 & desmosterol & 12.284 & 0.80 \\
8 & cholestanal & 12.384 & 0.30 \\
9 & lathosterol & 12.404 & 0.50 \\
& Total identified & & 99.60 \\
\hline
\end{tabular}

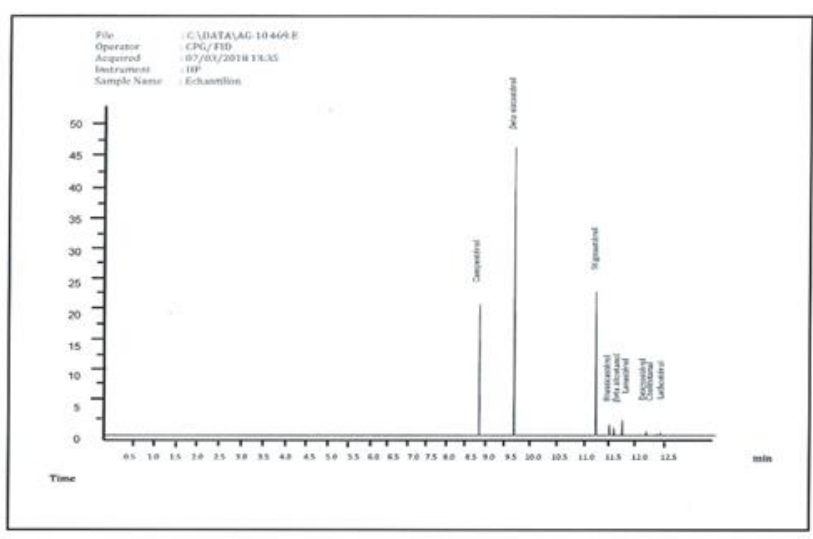

Fig. 2. Phytosterol GC chromatogram of pumpkin seed oil extract.

\section{CONCLUSION}

This project has determined fatty acids and phytosterols Cucurbita pepo (or pumpkin) seed oils extract, widely cultivated in Algeria. The results showed that Algerian pumpkin seeds contain appreciable amounts of unsaturated fatty acids and sterols.

This study could be preliminary leading to other experimental and clinical works to demonstrate that the pumpkin seeds oils can play a crucial role in the prevention from oxidative stress and the protection of the animal and human tissues against the toxicities induced by the herbicides used in Algeria.

\section{REFERENCES}

[1] Sayed Abou Seif H. Ameliorative effect of pumpkin oil (Cucurbita pepo L.) against alcohol-induced hepatotoxicity and oxidative stress in albino rats. Beni-suef university journal of basic and applied sciences. 2014; 3 (1): 78-85.

[2] Fruhwirth GO and Hermetter A. Seeds and oil of the Styrian oil pumpkin: components and biological activities, Eur. J. Lipid Sci. Technol. 2007; 109: 1128-1140.

[3] Abou-Zeid SM, AbuBakr HO, Mohamed MA, El-Bahrawy A. Ameliorative effect of pumpkin seed oil against emamectin induced toxicity in mice. Biomedicine \& Pharmacotherapy. 2018; 98: 242251.
[4] Aghaei S, Nikzad H, Taghizadeh M, Tameh AA, Taherian A, Moravveji A. Protective effect of Pumpkin seed extract on sperm characteristics, biochemical parameters and epididymal histology in adult male rats treated with Cyclophosphamide. Andrologia. 2013;19.

[5] Gossell-Williams M, Lyttle K, Clarke T, Gardner M, Simon O. Supplementation with pumpkin seed oil improves plasma lipid profile and cardiovascular outcomes of female non-ovariectomized and ovariectomized Sprague-Dawley rats. Phytotherapy Res. 2008; 22(7):873-7.

[6] Rezig L, Chouaibi M, Msaada K, Hamdi S. Chemical composition and profile characterisation of pumpkin (Cucurbita maxima) seed oil. Industrial Crops and Products. 2012; 37: 82-87.

[7] Mitra P, Ramaswamy HS, Chang KS. Pumpkin (Cucurbita maxima) seed oil extraction using supercritical carbon dioxide and physicochemical properties of the oil. J. Food Eng. 2009; 95: 208213.

[8] Abdullahi I and Santhose I. Comparative Analysis on Antioxidant and Antibacterial Activity of Pumpkin Wastes. J Antimicrob Agents. 2018; 4 (3): 1000180.

[9] Peiretti PG, Meineri G, Gai F, Longato E, Amarowicz R. Antioxidative activities and phenolic compounds of pumpkin (Cucurbita pepo) seeds and amaranth (Amaranthus caudatus) grain extracts. Natural Product Research. 2017; 31 (18): 2178-2182.

[10] Boaduo NK, Katerere D, Eloff JN, Naidoo V. Evaluation of six plant species used traditionally in the treatment and control of diabetes mellitus in South Africa using in vitro methods. Pharm. Biol. 2014; 52, 756-761.

[11] Nawirska-Olsza'nska A, Kita A, Biesiada A, Sokół-Ł_etowska A, Kucharska Z. Characteristics of antioxidant activity and composition of pumpkin seed oils in 12 cultivars. Food Chem. 2013; 139: 155161.

[12] Harishaoui RMA. Comparison of Antimicrobial Activity of Both Seeds and Leaves Extract of Two Type of Cucurbita pepo L. (Iraqi\&Chinese). J. of Kerbala University. 2011; 9 (4): 45-52.

[13] Metcalfe LD , Schmitz AA and Pelka JR. Rapid Preparation of Fatty Acid Esters from Lipids for Gas Chromatographic Analysis. 1966; 38 (3): 514-515.

[14] Benalia M, Djeridane A, Gourine N, Nia S, Ajandouz E, Yousfi M. Fatty acid profile, tocopherols content and antioxidant activity of algerian pumpkin seeds oil (Cucurbita pepo L). Med. J. Nutrition Metab. 2015; 8 (1): 9-25

[15] Bagepalli SAK, Kuruba L, Korala KN J, Devangam SS, Chinna S V, Bachappa M. Anti nociceptive and Antipyretic Activities of Amaranthus Viridis Linn in Different Experimental Models. Avicenna Journal of Medical Biotechnology. 2009; 1 (3).

[16] El-Adawy TA and Taha MK. Characteristics and Composition of Watermelon, Pumpkin, and Paprika Seed Oils and Flours. Agric. Food Chem. 2001; 49 (3): 1253-1259.

[17] EL-Masry SA. Effect of pumpkin oil and vitamin E on lead induced testicular toxicity in male rats. The Journal of Animal \& Plant Sciences. 2015; 25(1): 72-77. 